\title{
Analysis on the Growth Efficiency of the Pearl River Delta Real Economy From the Perspective of Financial Supply-Side Reform
}

\author{
Shizhong Xiong ${ }^{1, *}$ Xiaofang Xiong ${ }^{1}$
}

\author{
${ }^{1}$ Department of Accounting, Xinhua College of Sun Yat-Sen University, Dongguan, Guangdong, China \\ *Corresponding author. Email: xsz9293@126.com
}

\begin{abstract}
Finance is the blood and core of the modern real economy, leading the essentials of supply-side reforms and serving the real economy; financial supply-side reforms guide the direction of economic transformation and development, and it is our bounden duty to promote the development of efficient and high-quality real economy. Although the efficiency of financial supply has shown an upward trend, the flow of funds serving the real economy is still in a state of "intestinal infarction", which reflects the inefficiency of the financial supply system. With the aid of three level I indicators and 9 level II indicators of financial supply-driven efficiency, the financial supply system is evaluated, and the relationship between the financial supply system of the Pearl River Delta and the development of the real economy from 2011 to 2019 is explored using correlation theory. The correlation efficiency coefficient (interaction with the real economy) has shown a downward trend. It can be seen that dredging the flow of financial funds is like the "intestinal obstruction" of the real economy and improving the efficiency of financial supply has become a pain point in the reform of the financial supply side.
\end{abstract}

Keywords: financial supply-side reform, real economy, efficiency

\section{INTRODUCTION}

Finance is the blood and core of the modern real economy, leading the essentials of supply-side reforms and serving the real economy; financial supply-side reforms guide the direction of economic transformation and development, and it is our bounden duty to promote the development of efficient and high-quality real economy. During the nine years (2011-2019), the scale of social financing in the Pearl River Delta rose rapidly from 943.233 billion yuan to 2.355633 billion yuan. From the year-on-year growth of the social financial scale and the real economy, It can be seen that compared with the base period in 2010, the scale of social financing in the Pearl River Delta has shown a rising trend with greater fluctuations, and the real economy as a whole has shown a downward trend. The change in direction has greatly weakened its effectiveness in serving the real economy, fully demonstrating the misalignment of financial supply and demand and deviation from the real economy.

\section{LITERATURE REVIEW}

\section{A. Foreign research status}

Foreign scholars have conducted long-term and intense discussions on the relationship between the dynamics and results of the relationship between economic growth and financial structure. The focus is that finance is the core and driving force of economic development. Goldsmith (1969)put forward the theory of financial structure, laying the foundation for financial development and economic growth analysis. Mishkin (1973) financial deepening theory advocates that finance is the driving force and core of economic development. Levine et al. (1993)used 30-year data from 80 countries as the target, revised and supplemented when studying the relationship between financial development and economic growth, and developed the financial structure theory to affirm the non-neutral effect of financial structure on the real economy. Empirical studies on the relationship between financial markets and the real economy by Arestis (1997), Rousseau and Wachtel (2000), Bech and Levine (2004), Crochane (2006)and other scholars show: financial market and its stability, market rate of return, financial structure And other elements interact 
and influence economic growth. Anizoulatos et al. (2011), Oleg et al. (2013 research shows that finance uses technology as a carrier to effectively promote the development of the real economy. A few scholars, such as Alexiou et al. (2018), argue that financial intermediation and economic growth no longer show a significant interaction relationship after the crisis .

\section{B. Chinese research status}

As far as Chinese scholars are concerned, Tan Ruyong's (1999)research found that financial institutions have a positive and significant relationship with economic development. Li Maosheng et al. (2001), Han Tingchun (2001)and Sun Wuqin (2004)all advocate the positive coupling of financial structure optimization and economic structure to promote economic development, and conversely restrict economic development. Sun Jingde et al. (2012)and Li Xijiang (2012)believe that the financial structure and economic development are asymmetry, and the problem of regional financial structure development imbalance is prominent. The research of $\mathrm{Li}$ Qiang et al. (2013)shows that China's economy is showing a trend of "being out of reality". $\mathrm{Li}$ Miaomiao et al. (2015)pointed out that the coupling of financial technology is beneficial to economic growth. Yixin and Liu Fengliang (2015), Zhang Yichun and Wang Guoqiang (2015)believe that finance is the driving force and core of economic growth and leads the direction of real economy development. Matching. Liu Weijiang and Wang Hubang (2017)analyze the practical necessity of supply-side reforms and create external financial conditions for the development of the real economy. Long Haiming, Wu Di (2018), and Zhang Xiaobo (2018)propose through empirical analysis methods that the optimization of the financial supply structure can Correct the misallocation of financial resources and promote the development of the real economy. Wang Jun and Wang Kun (2018)advocate reasonable arrangements for the financial supply system to encourage innovation on the supply side of the financial market and promote economic development and growth.

To sum up, by combing and analyzing different literatures on economic development and financial structure optimization, it can be concluded that there are few quantitative studies on financial supply-side structural reforms and real economic development, and the theoretical framework system for research has not yet been formed. Empirical research is in its infancy. Starting from the reality that financial supply serves the development of the real economy, this article uses correlation theory to explore the correlation efficiency between the Pearl River Delta's financial supply and the growth of the real economy from 2011 to 2019, and proposes relevant suggestions for financial services to the real economy. Lane and Milesi (2003)and Liu
Shenglong and Zhang Jie (2009)et al. used the quantitative method of asset ratio (ratio of assets to GDP)to measure financial integration. The greater the value of this index is, the higher the measure of financial integration will be.

\section{REALISTIC ANALYSIS OF THE DISLOCATION OF FINANCIAL SUPPLY AND DEMAND}

\section{A. Financial supply is out of reality}

The development of finance and the real economy is like the relationship between water and fish. Fish cannot do without water. The pool is full and the fish sing; if the pond dries up, the fish will die. In recent years, as the economy has entered a new normal and financial supply reforms have deepened, financial supply has continued to innovate, financial products have been dazzling, and financial capital has flowed into the virtual economy. According to statistics from the Guangdong Provincial Statistical Yearbook, compared with 2018, the Pearl River Delta's financial industry added value in 2019 accounted for $3.36 \%$ of GDP, an increase of 0.07 percentage points, and from 2011 to 2019, it can be seen from 2011 to 20017 This indicator fluctuates at an average of $4.98 \%$. Due to the impact of financial supply-side reforms, this indicator will gradually drop by $3.36 \%$ from 2018 to 2019 , which is much higher than that of developed capitalist countries. Since this indicator objectively reflects the matching status of funds in the virtual and real economy, it can be seen that the flow of financial supply needed to serve the real economy forms a "gut obstruction", and the flow of supply funds in the virtual economy forms a "baotu spring". That is to say, a new situation has emerged in the relationship between financial supply and the real economy - financial supply is "off the real to the virtual", and the real economy is stagnating.

\section{B. The real economy is sluggish and financial supply is mismatched}

The real economy is the hub and cornerstone of the social economy, and the driving force for high-quality economic development comes from small and mediumsized enterprises. The Pearl River Delta small, medium and micro enterprises created $79.27 \%$ of the regional GDP in 2016 and provided 6.9193 million jobs; contributed $73.17 \%$ of the regional GDP in 2017 , driving 7,078,300 jobs; in 2018, they made a $69.57 \%$ contribution to the regional GDP, providing $6,618,700$ jobs were created. However, with the transformation of the focus of the contradiction between financial supply and demand and the spread and spread of the pressure of economic downturn, the financial institutions that provide the "blood" of capital flow for small, medium 
and micro enterprises-banks, think that the poor love the rich, the financial supply and demand are misaligned, and the effective financial supply is insufficient. Restrain the growth and development of the real economy. The mismatch of effective capital supply has caused the economy to lose its strong source of development power, which is specifically reflected in: the decline in economic growth, the decline in economic efficiency, the increase in unemployment, the increase in tax burden, and a small number of small and medium-sized enterprises that frequently go bankrupt. Since 2011-2019, the deposit-loan balance of financial institutions in the Pearl River Delta has shown an expansion trend. It has expanded from 2,644.156 billion yuan in 2011 to 5,332.941 billion yuan in 2019, and nearly $41.06 \%$ of the deposit-retaining financial institutions. In 2011, the real estate financial investment in the Pearl River Delta was 410.42 billion yuan, an increase of $31.6 \%$; in 2012 it rapidly increased to 448.367 billion yuan, an increase of $11.5 \%$, in 2013 it was 538.886 billion yuan, an average annual increase of $20.2 \%$, and in 2014 it was 629.355 billion yuan, an increase $17.4 \%$; 707.557 billion yuan in 2015, an increase of $12.4 \%$; 2016 investment was 860.117 billion yuan, an increase of $21.6 \%$; in 2017 it reached 982.778 billion yuan, an increase of $14.3 \%$; 2018 was $1,149.033$ billion yuan, an increase of $16.9 \%$; 2019 was $1,284,954$ million yuan , An increase of $11.8 \%$. In the past nine years, the average annual growth rate of investment in real estate development in the Pearl River Delta has been $17.53 \%$. Although the real estate industry has encountered macro-control, the inflow of funds in the real estate industry has increased year by year, resulting in a mismatch of financial credit resources and "influx", leading to the real economy (small, medium and micro enterprises)The funding needs are short of and "dried up".

\section{The financing cost of the real economy is high, and corporate financing is "unevenly hungry"}

Corporate financing needs are strong and financial supply is insufficient, leading to an increase in corporate financing costs. Expensive financing costs far exceed the carrying capacity of small, medium and micro enterprises, and the problem of expensive financing remains prominent. Due to the low operating efficiency of small, medium and micro enterprises, expensive financing costs inhibit their vision of lending. From the perspective of interest rates, the loan interest rate of financial institutions is a true portrayal of corporate financing costs. Compared with large enterprises in the Pearl River Delta, the average loan interest rate for small, medium and micro enterprises in financial institutions from 2011 to 2019 was $5.3 \%$, and it was adjusted to $4.89 \%$ in 2019 . , This loan interest rate is too high, resulting in expensive financing costs. From the perspective of financing costs, based on the monopoly and effectiveness of financial supply services, large enterprises have good credit standing and easy access to loans, low financing costs while small and medium enterprises have low credit, lack of assets and pledge rights, and can only be financed through private high-interest financing. The cost is high.

Taking the Pearl River Delta as an example, small, medium and micro enterprises have made outstanding contributions to the economic growth of the Pearl River Delta. Data shows that the added value of small, medium and micro enterprises accounted for $16.06 \%$ of the GDP of the Pearl River Delta in 2019, and that in $201815.74 \%$, paid 437.33 billion yuan in profits and taxes, provided 6.62 million jobs, $15 \%$ patents, $25 \%$ innovation results and $30 \%$ new products. However, in 2019, loans to small, medium and micro enterprises accounted for $8.14 \%$ of the balance of loans in the Pearl River Delta. In 2018, loans to small, medium and micro enterprises accounted for $8.26 \%$ of loans in the Pearl River Delta, far less than their contribution to the economy of the Pearl River Delta. At the same time, financial institutions in the Pearl River Delta have implemented a "credit system" for enterprises. Excellent small, medium and micro enterprises have repeated loans and credits, and the supply of loans exceeds demand; while ordinary small, medium and micro enterprises lack loans and credit, and the symptoms of "uneven hunger" in financing for small, medium and micro enterprises of different sizes remain exist.

\section{ANALYSIS OF THE CORRELATION EFFICIENCY BETWEEN THE FINANCIAL SUPPLY- SIDE REFORM DRIVE AND THE DEVELOPMENT OF THE REAL ECONOMY}

\section{A. Definition of research methods}

Since the data collected in the study is limited to the period from 2011 to 2019 , the sample is small and the information is lacking, so it is not suitable for Granger causality analysis, and the gray relational theory has the research focus on the uncertainty of "small samples, poor information" The characteristics can explain the relationship between variables in detail. Therefore, this paper adopts the gray correlation theory analysis method to dynamically explore the financial supply of the Pearl River Delta and the development of the real economy.

\section{B. Variable description and data sources}

Corresponding to the virtual economy, the real economy refers to the economy other than the virtual economy such as the financial industry and the real estate industry. The level of the real economy is determined by GDP-( $\left.\mathrm{FI}_{\mathrm{gdp}}+\mathrm{REI}_{\mathrm{gdp}}\right)$. $\mathrm{FI}_{\mathrm{gdp}}$ is the output 
value of the financial industry, and $R E I_{\text {gdp }}$ is the output value of the real estate industry. For the selection of financial supply-side reform indicators, refer to the thinking method of Zhong Yun (2015), Zhang Zhiyuan, etc. (2018), select financial primary efficiency, financial comprehensive efficiency and financial scale efficiency indicators $\mathrm{I}$ and their corresponding indicators II, such as residential deposits The $\mathrm{X}_{1}$ variable reflects the residents' demand for currency and investment behavior; $X_{2}$ reflects the operating efficiency of bank assets and the size of the risk coefficient; $\mathrm{X}_{3}$ reflects the security information of bank assets. $X_{4}$ represents the contribution of the added value of the financial industry to the regional GDP, $\mathrm{X}_{5}$ indicates the contribution of the added value of the financial industry to the regional social welfare; $\mathrm{X}_{6}$ reflects the productivity of financial services in the region; $\mathrm{X}_{7}$ reflects the amount of financing in the region's GDP; $X_{8}$ indicates the size of financial assets ; $\mathrm{X}_{9}$ reflects the size of the correlation between regional economy and insurance. The index system is shown in "Table I". The data comes from China Financial Statistical Yearbook and Guangdong Statistical Yearbook

TABLE I. FINANCIAL SUPPLY AND REAL ECONOMY INDICATOR SYSTEM

\begin{tabular}{|c|c|c|c|c|}
\hline & Index ( I )level & Index ( II )level & Variable & Index ( II )Interpretation \\
\hline $\begin{array}{ll}\text { Real economy } \\
\text { level }\end{array}$ & Real economy & $\begin{array}{l}\text { Real } \\
\text { economy output }\end{array}$ & $X_{0}$ & $\begin{array}{l}\text { The difference between GDP and virtual economic } \\
\text { output value GDP }\end{array}$ \\
\hline \multirow{9}{*}{$\begin{array}{l}\text { Financial } \\
\text { supply side } \\
\text { reform }\end{array}$} & \multirow[t]{3}{*}{$\begin{array}{l}\text { Financial Junior } \\
\text { Drive efficiency }\end{array}$} & $\begin{array}{l}\text { Proportion of Resident } \\
\text { Deposits }\end{array}$ & $X_{1}$ & The ratio of deposits to GDP \\
\hline & & Deposit ratio & $X_{2}$ & Ratio of loan amount to deposit amount \\
\hline & & $\begin{array}{l}\text { Bad debt rate (i.e. bad } \\
\text { debt rate) }\end{array}$ & $X_{a}$ & Ratio of non-performing loans to total loans \\
\hline & \multirow{3}{*}{$\begin{array}{l}\text { Financial } \\
\text { synthesis } \\
\text { Drive efficiency }\end{array}$} & $\begin{array}{l}\text { Proportion of financial } \\
\text { industry output value }\end{array}$ & $X_{4}$ & The ratio of financial industry value-added to GDP \\
\hline & & $\begin{array}{l}\text { Per capita financial } \\
\text { products accounted for }\end{array}$ & $X_{5}$ & $\begin{array}{l}\text { The ratio of the value-added of the financial } \\
\text { industry to the regional population }\end{array}$ \\
\hline & & $\begin{array}{l}\text { Financial industry } \\
\text { productivity }\end{array}$ & $X_{6}$ & $\begin{array}{l}\text { The ratio of the value-added of the financial } \\
\text { industry to the employment population in the } \\
\text { financial industry }\end{array}$ \\
\hline & \multirow[t]{3}{*}{$\begin{array}{l}\text { Financial scale } \\
\text { Drive efficiency }\end{array}$} & $\begin{array}{l}\text { Proportion of total } \\
\text { financing }\end{array}$ & $X_{7}$ & Ratio of total financing to GDP \\
\hline & & Financial related ratio & $X_{\mathrm{g}}$ & Ratio of total financial assets to GDP \\
\hline & & $\begin{array}{l}\text { Proportion of insurance } \\
\text { income }\end{array}$ & $X_{9}$ & The ratio of total insurance income to GDP \\
\hline
\end{tabular}

\section{Determining the correlation efficiency coefficient}

Due to the different dimensions of the system factors and the heterogeneity of the magnitude of the values, it is not easy to directly compare. Therefore, it is necessary to perform dimensionless processing on the original data and replace them with data sequences that are easy to compare. Based on the above reasons, the extreme value method is used for the original bad debt rate data, and the average value method is used for other data.

If the variable changes are convergent, that is, the degree of synchronous change is higher, the efficiency coefficient of the variable correlation process is larger; on the contrary, the opposite is true. This study takes the real economic variable $\mathrm{X}_{0}$ of the Pearl River Delta as the reference sequence, and 9 financial efficiency indicators as the factor subsequences, the value of the resolution coefficient $\xi$ is defined as $\xi=0.5$, and the correlation efficiency coefficient between the real economic indicators and the financial efficiency indicators is calculated. The formula is as follows:
Let the reference sequence:

$$
X_{0}=\left[X_{0}(k), k=1,2, \cdots, n\right] .
$$

The factor subsequence is:

$$
X_{i}=\left[X_{i}(k), k=1,2, \cdots, n\right], \quad(\mathrm{i}=1,2, \cdots, \mathrm{m})
$$

Then the correlation efficiency coefficient of $\mathrm{X}_{0}$ and $\mathrm{Xi} \square \mathrm{r}\left(\mathrm{x}_{0}, \mathrm{xi}\right)$ is defined as:

$$
r\left(X_{0}, X_{i}\right)=\frac{1}{n} \sum_{k=1}^{n} r\left(X_{0}(k), X_{i}(k)\right)
$$

Among them,

$$
\begin{aligned}
& r\left(X_{0}(k), X_{i}(k)\right) \\
& =\frac{\min _{i} \min _{k}\left|X_{0}(k)-X_{i}(k)\right|+\xi \operatorname{MaxMax}_{i}\left|X_{0}(k)-X_{i}(k)\right|}{\left|X_{0}(k)-X_{i}(k)\right|+\xi \operatorname{MaxMax}_{i}\left|X_{0}(k)-X_{i}(k)\right|}
\end{aligned}
$$

$\xi$ is the resolution coefficient, $\xi \in[0,1]$. $\mid \mathbf{X}_{\mathbf{0}}(\mathbf{k})-\mathbf{X i}$ (k) $\mid$ is the absolute difference between the reference sequence and the factor subsequence, 


$$
\min _{i} \min _{k}\left|X_{0}(k)-X_{i}(k)\right|
$$

is the minimum value of the absolute difference, $\underset{i}{\operatorname{Max} \underset{k}{\operatorname{Max}}\left|X_{0}(k)-X_{i}(k)\right|}$ is the
maximum value of absolute difference, $\mathrm{n}=10, \mathrm{~m}=9$.

All $\mathrm{m}$ sequence association degrees $\mathrm{r}\left[\mathrm{X}_{0}(\mathrm{k}), \mathrm{X}_{\mathrm{i}}(\mathrm{k})\right]$ are arranged to obtain an association sequence set, and then determine the correlation coefficient between $X_{i}$ and $\mathrm{X}_{0}$. "Table II" shows the correlation efficiency coefficient between the real economic indicators of the Pearl River Delta and the financial-driven efficiency indicators calculated.

TABLE II.

CORRELATION EFFICIENCY COEFFICIENT MATRIX AND RANKING OF CORRELATION EFFICIENCY

\begin{tabular}{|l|l|l|l|l|l|l|l|l|l|l|}
\hline \multirow{2}{*}{} & \multicolumn{3}{|l}{$\begin{array}{l}\text { Financial Junior } \\
\text { Drive efficiency }\end{array}$} & \multicolumn{2}{l|}{$\begin{array}{l}\text { Financial synthesis } \\
\text { Drive efficiency }\end{array}$} & \multicolumn{2}{l|}{$\begin{array}{l}\text { Financial scale } \\
\text { Drive efficiency }\end{array}$} \\
\cline { 2 - 10 } & $X_{1}$ & $X_{2}$ & $X_{\mathrm{a}}$ & $X_{4}$ & $X_{5}$ & $X_{6}$ & $X_{7}$ & $X_{\mathrm{g}}$ & $X_{\mathrm{g}}$ & \\
\hline 2011 & 1.127 & 0.504 & 0.933 & 0.870 & 0.568 & 0.654 & 1.000 & 0.710 & 0.933 & 1.1127 \\
\hline 2012 & 0.517 & 0.542 & 0.399 & 0.516 & 0.836 & 0.706 & 0.443 & 0.666 & 1.000 & 1.000 \\
\hline 2013 & 0.662 & 0.753 & 0.365 & 0.666 & 0.822 & 0.780 & 0.888 & 0.856 & 1.000 & 1.000 \\
\hline 2014 & 0.797 & 0.776 & 0.355 & 0.515 & 0.584 & 0.570 & 0.453 & 1.000 & 0.849 & 1.000 \\
\hline 2015 & 1.000 & 0.856 & 0.844 & 0.493 & 0.563 & 0.543 & 0.369 & 0.997 & 0.943 & 1.000 \\
\hline 2016 & 0.691 & 0.670 & 0.493 & 0.711 & 0.576 & 0.692 & 0.342 & 1.000 & 0.663 & 1.000 \\
\hline 2017 & 0.573 & 0.674 & 0.391 & 0.625 & 0.881 & 0.776 & 0.697 & 0.838 & 1.000 & 1.000 \\
\hline 2018 & 0.579 & 0.688 & 0.347 & 0.427 & 0.502 & 0.490 & 0.767 & 0.736 & 1.000 & 1.000 \\
\hline 2019 & 1.511 & 0.736 & 0.346 & 0.502 & 0.594 & 0.589 & 1.000 & 0.799 & 0.894 & 1.511 \\
\hline$r_{\mathrm{I}}$ & 0.740 & 0.620 & 0.441 & 0.520 & 0.573 & 0.563 & 0.596 & 0.760 & 0.735 & \\
\hline Association sort & 2 & 4 & 9 & 8 & 6 & 7 & 5 & 1 & 3 \\
\hline
\end{tabular}

The correlation efficiency coefficient and the ranking of correlation degree are shown in "Table II". In the 10 years from 2011 to 2019, the proportion of total financial assets $\left(\mathrm{X}_{8}\right)$ has the highest correlation with the real economy, followed by the proportion of household deposits $\left(\mathrm{X}_{1}\right)$, and the third is the proportion of insurance income $\left(\mathrm{X}_{9}\right)$. Other variables are related The efficiency coefficients are arranged in order of largest to smallest: loan-to-deposit ratio $\left(\mathrm{X}_{2}\right)$, total financing ratio $\left(\mathrm{X}_{7}\right)$, per capita financial product ratio $\left(\mathrm{X}_{5}\right)$, financial industry productivity $\left(\mathrm{X}_{6}\right)$, financial industry output value $\left(\mathrm{X}_{4}\right)$, bad debts Rate $\left(\mathrm{X}_{3}\right)$. Observing the maximum value of the correlation efficiency coefficient each year, the maximum value shows a downward trend, which means that the matching of financial supply and demand is misaligned, and the correlation efficiency coefficient (interaction with the real economy)basically shows a downward trend.

\section{Analysis of correlation efficiency}

Using the financial supply system as a starting point, calculate the arithmetic mean $Y_{n}(K)$ of the subsequence indicators of each factor, construct the value of the reference object of the indicator I related to the real economy, define $n=1$ as the primary financial driver, $n=2$ Financial integration drive, $n=3$ financial scale drive, $\mathrm{k}=1,2,3, \ldots, 10$. In order to explore the degree of correlation between financial primary driving efficiency, financial comprehensive driving efficiency, financial scale driving efficiency and real economy development, as shown in "Table III".

TABLE III. THE DEGREE OF CORRELATION BETWEEN FINANCIAL-DRIVENEFFICIENCY AND THE DEVELOPMENT OF THE REAL ECONOMY

\begin{tabular}{|l|l|l|l|}
\hline & $\begin{array}{c}\text { Financial Junior } \\
\text { Drive efficiency }\end{array}$ & $\begin{array}{c}\text { Financial synthesis } \\
\text { Drive efficiency }\end{array}$ & $\begin{array}{c}\text { Financial scale } \\
\text { Drive efficiency }\end{array}$ \\
\hline 2011 & 0.855 & 0.697 & 0.881 \\
\hline 2012 & 0.501 & 0.686 & 0.703 \\
\hline 2013 & 0.593 & 0.756 & 0.915 \\
\hline 2014 & 0.696 & 0.556 & 0.767 \\
\hline 2015 & 0.900 & 0.503 & 0.770 \\
\hline 2016 & 0.618 & 0.660 & 0.668 \\
\hline 2017 & 0.546 & 0.761 & 0.845 \\
\hline 2018 & 0.531 & 0.533 & 0.834 \\
\hline 2019 & 0.864 & 0.562 & 0.898 \\
\hline
\end{tabular}




\section{CONCLUSION}

Based on the above correlation efficiency coefficient matrix and efficiency analysis, the conclusions are as follows:

First, the primary driving efficiency of the Pearl River Delta has a relatively large correlation coefficient with the growth of the real economy. The proportion of residents' deposits has gradually increased the driving force for the growth of the real economy. The bad debt ratio has a greater negative effect on the real economy. The loan-to-deposit ratio of banks and other financial institutions has the smallest correlation efficiency coefficient with the growth of the real economy, indicating that banks and small, medium and micro enterprises have funds. Flow channels are blocked, leading to high corporate debt. Since the financial supply-side reform in 2016, the proportion of deposits of the Pearl River Delta residents has been decreasing, and the correlation coefficient between the primary financial driving efficiency and the real economy has declined slightly. However, the development of the real economy in the Pearl River Delta still gains lasting momentum.

Second, the comprehensive driving efficiency of the Pearl River Delta has a relatively large correlation coefficient with real economic growth, but the contribution of the financial industry's value-added to GDP is small, the per capita share of financial products and the financial industry's production efficiency are low, and the goal of economic growth has not been achieved. With the deepening of financial supply-side reforms, the value-added effect of the Pearl River Delta's financial industry on GDP has gradually increased, and financial supply products continue to innovate and increase. From the perspective of comprehensive financial driving efficiency, the supply of financial products in the Pearl River Delta has greatly improved Space, the supply and demand of financial products are misaligned with the products required for the development of the real economy, thereby inhibiting the harmonious development of an effective financial supply and demand structure.

Third, the financial scale-driven efficiency of the Pearl River Delta has the largest correlation coefficient with the development of the real economy. Although the proportion of total financing in the Pearl River Delta and financial-related ratios continue to increase, and the amount of insurance income has increased, the increase in financing scale and the transformation of the power to promote the real economy are still misaligned, resulting in "uneven hunger" and lagging development in the real economy. This shows that the financial supply and demand system has not magnified its effectiveness in serving the real economy.

\section{References}

[1] Goldsmith R W. Financial Structure and Development [M].New Haven, CT: Yale University Press, 1969.21-35.

[2] McKinnon R.I. , Money and Capital in Economic Development [M]. Washington, D.C.: Brookings Institution Press, 1973.

[3] King R G, R. Levine.. Finance and Growth: Schumpeter Might be Right[J]. Quarterly Journal of Economics, 1993, 108(3):717737.

[4] Arestis, P, P. Demetriades. Financial Development and Economic Growth: Assessing the Evidence [J]. Economic Journal, 1997, 107:783-799

[5] Rousseau, P. L., P. Wachtel. Equity Markets and Growth: Cross - Country Evidence on Timing and Outcomes, 1980-1995[J] Journal of Business and Finance, 2000, 24:1933-1957.

[6] Beck, T. and R. Levine. Stock Markets ,Banks and Growth : Panel Evidence $[\mathrm{J}]$. Journal of Banking and Finance, 2004:423 -442 .

[7] Crochane J H . Financial Markets and the Real Economy[J] Social Science Electronic Publishing, 2006, 1(1):237-325.

[8] Anizoulaos A A, Apergis N, Tsoumas C. Financial structure and industrial structure[J]. Bulletin of Economic Research, 2011, 63(2):109-139.

[9] Badunenko O, Romero-Avila, Diego. Financial development and the sources of growth and convergence[J].International Economic Review, 2013, 54(2):629-663.

[10] Alexiou C , Vogiazas S , Nellis J G. Reassessing the relationship between the financial sector and economic growth: Dynamic panel evidence[J]. International Journal ofFinance \& Economics, 2018,(23):155-173.

[11] Tan Ruyong. An Empirical Study on the Relationship between China's Financial Development and Economic Growth [J] Economic Research, 1999, (10):53-61

[12] Li Maosheng, Li Guangrong. Research on the optimization of economic structure and financial structure at the beginning of the new century $[\mathrm{J}]$. Economic Research on Finance Theory and Practice, 2001, (6)17-24.

[13] Han Tingchun. Financial Development and Economic Growth: An Empirical Analysis Based on China[J]. Economic Science, 2001, (3): 31-40.

[14] Sun Wuqin. On the adaptation efficiency of financial structure and real economy [J]. Management World, 2004, (5): 134-135.

[15] Sun Jingde, Yu Xiamin. The case of Ningbo on the relationship between financial structure and macroeconomic structure $[\mathrm{J}]$ Shanghai Finance, 2012, (8): 21-25

[16] Li Xijiang. Economic structure adjustment and financial tool selection: from regional differences $[\mathrm{J}]$. Reform, 2012, (8): 25 30 .

[17] Li Qiang, Xu Kangning. Financial Development, Real Economy and Economic Growth - An Empirical Analysis Based on Provincial Panel Data[J]. Shanghai Economic Research, 2013, (9): 3-11

[18] Li Miaomiao, Xiao Hongiun, Zhao Shuang. Research on the Relationship between Financial Development, Technological Innovation and Economic Growth-Based on China's Provincial and Municipal Panel Data[J]. Chinese Management Science, 2015, (2):162-169.

[19] Yi Xin, Liu Fengliang. Financial Development, Technological Innovation and Industrial Structure Transformation: A Theoretical Analysis Framework of Multi-sector Endogenous Growth[J]. Management World, 2015, (10): 24-39.

[20] Zhang Yichun, Wang Guoqiang. Research on the Unbalanced Relationship between Financial Development and Real Economic Growth - Based on the Empirical Analysis of 
Double Threshold Regression[J]. Contemporary Finance, 2015, (6): 45-54.

[21] Zhong Yun, Wu Meng. Research on the convergence of service industry development under the background of regional cooperation - Taking the financial industry of the Greater Pearl River Delta as an example[J]. Tropical Geography, 2015, 35(2): 147-153.

[22] Liu Weijiang, Wang Hubang. Analysis of the spatial effect of financing structure on the development of the real economy under the supply-side structural reform[J]. Quantitative Economics and Technical Economics Research, 2017, (2):1-14.

[23] Long Haiming, Wu Di. The path choice for financial development to promote structural reform on the supply side of the industry[J]. Finance Theory and Practice, 2018, (4):21-28.

[24] Zhang Xiaobo. Analysis of the dynamic relationship between financial supply-side structural reforms, consumer demand and economic growth[J]. Statistics and Decision, 2018, (15):158161.

[25] Wang Jun, Wang Kun. Research on the Asymmetric Effects of my country's Financial Development and Economic Growth[J]. Statistics and Decision, 2018, (9): 150-154.

[26] Zhang Zhiyuan, Ma Yongfan, Hu Xingcun. Research on the Coupling Effect of Financial Supply-side Reform and the Conversion of Old and New Kinetic Energy-Taking Shandong Province as an Example[J]. Dongyue Lun, 2018, (10): 44-54. 